\title{
The Lung Health Study
}

\author{
J MANFREDA MD, NR ANTHONISEN MD PhD AND THE LUNG HEALTH STUDY RESEARCH GROUP \\ Faculty of Medicine, University of Manitoba, Winnipeg, Manitoba
}

\section{J Manfreda, NR Anthonisen and the Lung Health Study REsearch Group. The Lung Health Study. Can Respir J 1995;2(2):104-111.}

OB.JECTIVE: To determine whother smoking intervention and use of an inhaled bronchodilator can slow the rate of decline in forced expiratory volume in $I s\left(F E V_{1}\right)$ in smokers with mild obstructive pulmonary disease.

DESIGN: Randomized clinical trial: participants random ized to one of three groups: smoking intervention plus inhated bronchodilator (Atrovent; ipratropium bromide) (SIA): smoking intervention plus placebo (SIP); or no intervention (usual care, UC).

SETTING: Ten centres in the United States and Canada.

Participants: A total of 5887 smokers, aged 35 to 60 years, with $\mathrm{FEV}_{1} 55$ to $90 \%$ predicted and $\mathrm{FEV} /$ /forced vital capalcity (FVC) less than $70 \%$.

INTER VENTIONS: Smoking intervention: intensive program combining behaviour modification and use of nicotine gum, with a subsequent matintenance progranı to prevent relapse. Bronchodilator: ipratropium bromide, two pulfs three times daily from a metered dose inhaler.

Main Outcome Measures: Change in FEV ${ }_{I}$ over a five-year period.

RESUlTS: Sustained smoking cessation was ichieved in $22 \%$ of both intervention groups (SIA, SIP), compared with $5 \%$ in UC. Both SIA and SIP groups showed significantly smaller declines in postbronchodilator FEV 1 over the five years of the study $-184 \mathrm{~mL}$ and $209 \mathrm{~mL}$, respectively, compared with $267 \mathrm{~mL}$ in UC. This difference was accounted for by an increase in FEV 1 in the SIA $(+39 \mathrm{~mL})$ and SIP $(+I 1 \mathrm{~mL})$ groups in the first year of the study, compared with a decline in UC $(-34 \mathrm{~mL})$. Those who achieved sustaincd smoking cessation experienced the greatest benefit. cvident for the five years of study. There was a smali noncumulative benefit associated with use of the active bronchodilator, which disappeared after the bronchodilator was discontinued.

CONCLUSIONS: An effective smoking intervention program significantly reduced decline in $\mathrm{FEV}_{\mathrm{I}}$ in smokers with mild airways obstruction. Use of an inhaled anticholinergic bronchodilator did not influence the long term decline of FEV

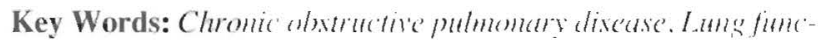
tion changes, Smokin:?

\section{The Lung Health Study}

OBJECTIF : Déterminer si un programme d’intervention auprès des fumeurs et I'utilisation d'un bronchodilatateur sn inhalation peut ralentir le taux de chute du volume expiratoire maximum/seconde (VEMS) chez des fumeurs atteints d'une maladie pulmonaire obstructive modérée.

Modèle : Essai clinique randomisé. Les participants ont été randomisés dans l'un des trois groupes suivants : intervention auprès des fumeurs associée à l'utilisation d'un bronchodilitateur en inhalation (Atrovent; bromure d'ipratropium) (IFA); intervention auprès des fumeurs associée à un placebo (IFP); aucune intervention (soins usuels, SU).

Contexte : Dix centres aux États-Unis et au Canada.

PARTicipants : Un total de 5887 fumeurs, âgés de 35 à 0() inls. avec un VEMS de 55 à $90 \%$ de la valeur théorique et un rapport VEMS/CVF (capacité vitale forcée) inférieur à $70 \%$.

INTERVENTIONS : Intervention auprès des fumeurs : programme intensif combinant modification des comportements et utilisation de la gomme à la nicotine suivi d'un programme d'entretien pour prévenir les rechutes. Bronchodilatateur : bromure d'ipratropium, deux bouffées trois fois par jour par inhalateur-doseur.

Mesures des Principaux Résultats : Changement du VEMS sur une période de 5 ans.

RÉSultats : Un arrêt soutenu du tabac a été observé chez $22 \%$ des participants des deux groupes d'intervention (IFA, IFP), comparativement à $5 \%$ dans le groupe recevant des soins usuels (SU). Les groupes IFA et IFP ont démontré une chute nettement plus faible du VEMS après l'utilisation d'un bronchodilatateur pendant la période d'étude de 5 ans - respectivement de $184 \mathrm{ml}$ et de $209 \mathrm{ml}$, comparée à $267 \mathrm{ml}$ pour le groupe SU. La différence s'explique par une augmentation du VEMS dans le groupe IFA $(+39 \mathrm{ml})$ et dans le groupe IFP $(+11 \mathrm{ml})$ pendant la première année de l'étude, comparativement à une chute du VEMS $(-34 \mathrm{ml})$ dans le groupe SU. Les participants qui ont réussi à cesser de fumer pendant une période soutenue ont présenté une nette amélioration pendant les 5 années d'étude. On a observé une légère amélioration non cumulative du VEMS associée à l'utilisation d'un bronchodilatateur actif qui disparaissait lorsque son emploi cessait.

ConClusions : Un programme d'intervention efficace auprès des fumeurs a sensiblement freiné la chute du VEMS chez les fumeurs atteints d'une maladie pulmonaire obstructive modérée. L'utilisalion d'un bronchodilatateur anticholinergique par inlatation 11 it pas su deffect sur la chute à long terme du VEMS. 
$\mathrm{T}$ He Lung Health Study (LhS) Was a Multicentre clinical trial designed to determine whether clinically overt chronic obstructive pulmonary disease (COPD) could be prevented by effective inlervention in the preclinical phase of the disease. Its design and protocol were developed in 1985-86, recruiting was begun in 1987, the follow-up phase was completed early in 1994, and the main results were reported later that year (1). This paper reviews the study and its available results and tries to indicate what is likely to be learned from further analysis of the enomous amount of data generated. The authors were involved in the LHS as the coprincipal investigators at one of the clinical centres at the University of Manitoba.

The interventions chosen as the best candidates to alter the course of COPD were smoking cessation and bronchodilator administration. The former needs liule justilication, but it is worth noting that all previous studies of the effect of smoking cessation involved nonrandomly assigned groups of people who had or had not stopped. Therefore, it was conceivable that the putative effects of smoking cessation were really only describing other characteristics of those individuals who, for whatever reason, were able to stop. The second intervention, bronchodilator therapy, was rationalies in two ways. First, there was some evidence that bronchodilator therapy slowed decline of lung function in bronchodilator responsive COPD patients (2). Second, if the 'Dutch hypothesis' (3) is correct, ie, the loss of lung function in COPD is related to airways reactivity, then prevention of bronchospasm, a presumed consequence of reactivity, might prevent lung function loss. As noted above, the interventions studied, and therefore the hypotheses tested by the LHS, were formulated 10 years ago.

\section{METHODS}

Design: Details of the design of the I.HS were descibed previously (4). Briefly, the plan was to measure the effect of the interventions on rate of change in lung function (forced expiratory volume in $\left.1 \mathrm{~s}\left[\mathrm{FEV}_{1}\right]\right)$ in people thought to be at high risk for symptomatic COPD. These were defined as cigarette smokers aged 35 to 60 years with airways obstruction, defined as $\mathrm{FEV}_{\mathrm{I}}$ /forced vital capacity (FVC) below $70 \%$. Individuals were randomly assigned to one of three groups: usual care (UC), who received no intervention; special intervention placebo (SIP), who were given a smoking cessation program and a placebo inhaler (Boehringer Ingelheim Pharmaceutical Inc, Connccticut); and special intervention Atrovent (SIA), who received a smoking cessation program and were asked to use inhaled ipatropium bromide (Boehringer Ingelheim) regularly. Each group was followed for five years with annual lung function measurement.

The size of the study was dictated by the size of hypothetical treatment effects of smoking cessation and bronchodilators diluted by less than optimal compliance with the interventions. With treatment effects of 15 to $30 \mathrm{~mL} /$ year on ammual change in FEV 1 , a $5(1) \%$ compliance rate with bronchodilator therapy and a $151020 \%$ increase in smoking cessation due to the intervention program, adequate statistical power would be avatable if each treattment group had $20(0)$ participants, ie, 6000 in the culire LHS and $6(1)$ at cach of 10 clinical centres.

Recruitment and entry criteria: Recruitment was carricd out by screening all available age-eligible smokers. Age eligibility was defined as 35 to 60 years, and smoking was defined as the consumption of at least 10 cigarctles on onc day in the preceding 30 . Screening essentially separated such people with $\mathrm{FEV}_{1} / \mathrm{FVC}$ below $75 \%$ from those with higher ratios. Smokers were accessed by a witc variety of methods, which differed among clinical centres $(5)$.

Willing subjects with FEV /FVC helow 75\% were asked to attend the clinic for final determination of eligibility. This included spromery before and after isoproterenol, and a questionnaire to detect potential confounders of results such as doctor prescribed bronchodilators, beta-blockers or other serious diseases; each of these was an exclusion criterion. Smokers without reasons for exclusion aged 35 to 60 were eligible for the LHS if their prebronchodilator $\mathrm{FEV}_{1} / \mathrm{FVC}$ was $70 \%$ or less and their FEV I was 55 to $\%(1 \%$ o ol predicted nomat. Willing individuals who ned these criteria were asked to attend the clinic for a third examination, at which at detailed respiratory history was taken and a methacholinc challenge administered. They then were randonized to onc of the three treatment groups.

Spirometry: Spirometry at initial recruiting screens was not rigidly controlled, but all subsequent spirometry was gov. emed by a detailed and demanding protocol (6). All clinical centres used the same equipment and softwarc. Acceptable expiratory manoeuvres were characterized in terms of smoothness, length, rapidity of start and effort ats defined by peak flow. Three acceptable manoeuvres were required lor eligibility with peak flows of $90 \%$ of the maximum or more. Two manoeuvres had to agree within $10 \%$ for peak flow and the larger of $0.1 \mathrm{~L}$ or $5 \%$ for FEV I and $0.2 \mathrm{~L}$ or $5 \%$ for FVC. Efforts were made to achieve similat quality all all centres throughout the study and fechnical performance was checked at site visits. The single largest values of $\mathrm{FEV}_{1}$ and $\mathrm{FVC}$ recorded at a session were taken as the values characteristic of an individual participant.

Bronchodilator response was measured spirometrically (see above) 5 mins after two puffs (200 g) of isoproterenol. Methacholine response wats measured spirometrically after successive inhalations of aerosols containing diluent and methacholine concentrations of $\mathrm{I}, 5,10$ and $25 \mathrm{~m} \mathrm{~m} / \mathrm{mL}$.

Interventions and compliance checks: The smoking cessation program was standardized and extremcly intensive (7). Special intervention participants were intervicwed at random by a physician who urged them to stop smohing on the basis of their airways obstruction. The subsequent intervention program was organized in groups that included participants' 'significant others', and which were guided by experienced health educators. Groups employed behavioural techniques amplified by group dynamics and supported hy liberal use of nicotine gum (Nicorette, Marion Merrell Dow Inc, Missouri). There were 12 scheduled group meetings beginning at four per week and decreasing in frequency over a total of 10 weeks. Quitters were followed very closely with a maintc- 
TABLE 1

Selected baseline characteristics

\begin{tabular}{|c|c|c|c|}
\hline Baseline characteristics & SIA $(n=1961)$ & $\begin{array}{l}\text { Study group } \\
\text { SIP }(n=1962)\end{array}$ & UC $(n=1964)$ \\
\hline Age (years) & $48.4 \pm 6.8$ & $48.6 \pm 6.8$ & $48.4 \pm 6.9$ \\
\hline Male $(\%)$ & 60.8 & 64.0 & 63.8 \\
\hline Pack-years & $40.4 \pm 19.7$ & $40.4 \pm 18.8$ & $40.5 \pm 18.9$ \\
\hline Cigarettes/day & $31.2 \pm 13.2$ & $31.5 \pm 12.6$ & $31.1 \pm 12.8$ \\
\hline Age started smoking & $17.5 \div 3.9$ & $17.4 \pm 3.9$ & $17.6 \pm 3.8$ \\
\hline FEV, postbronchodilator (L) & $2.73 \pm 0.64$ & $2.75 \pm 0.62$ & $2.76 \pm 0.62$ \\
\hline FEV $1, \%$ predicted & $75.1 \pm 8.8$ & $75.2 \pm 8.8$ & $75.1 \pm 8.8$ \\
\hline FEV, FVC $(\%)$ & $62.9 \pm 5.6$ & $63.0 \pm 5.5$ & $62.9 \pm 5.5$ \\
\hline Bronchodilator response (\% FEV 1 ) & $4.2+5.2$ & $4.4 \pm 5.1$ & $4.2 \pm 5.1$ \\
\hline \multicolumn{4}{|l|}{ Methacholine reactivity } \\
\hline Asthma (\%) & 7.6 & 7.2 & 6.8 \\
\hline Bronchitis (\%) & 31.8 & 29.6 & 28.4 \\
\hline Emphysema (\%) & 3.4 & 2.6 & 3.3 \\
\hline
\end{tabular}

Data are mean \pm SD. FEV 1 Forced expiratory volume in $1 \mathrm{~s}$; FVC Forced vital capacity; SIA Smoking intervention plus bronchodilator; SIP Smoking intervention plus placebo: UC Usual care. Feproduced with permission from reference 1, copyright 1994, American Medical Association

nance program built upon the initial experience, with attention to problems such as stress and weight gain. Relapsers were given either individual or group programs at the earliest opportunity.

Compliance with the smoking cessation intervention was checked at clinic visits every four months. A smoking history was taken and expired carbon monoxide measured. At annual visits a salivary sample was taken for cotinine measurement. Cotinine values of $20 \mathrm{mg} / \mathrm{mL}$ or less were taken as indicative of nonsmoking in participants who were not on nicotine replacement therapy; in those who were, carbon monoxide levels of $10 \mathrm{ppm}$ or less indicated abstinence.

SIA and SIP participants were instructed in the use of metered dose inhalers, and each was given a supply of inhalers in double blind fashion: neither participant nor investigator knew whether the participant had been assigned ipratropium bromide or placebo. Participants were instructed to inhale two puffs of medication ( $36 \mu \mathrm{g}$ ipratropium) tid. Compliance was checked every four months by self-report and by weighing returned inhaler cannisters. Twice daily inhaler use was accepted as adequate compliance.

Follow-up: Great efforts were expended to obtain annual follow-up data, including local and remote home visits. When study personnel and participants could not meet face to face, an interview was done by telephone when possible.

Follow-up visits involved repeat spirometry measurements before and after bronchodilator, detailed respiratory and smoking histories, and checks of inhaler compliance. If participants had a history of hospitalization, the relevant records were sought, and these plus any records associated with patient mortality were evaluated by an independent group of physicians who were blinded to treatment assignment. Smoking status was assessed by self-report, and carbon monoxide and continine measures and inhaler compliance were assessed by self-report and cannister weight. If a participant did not attend a visit, he or she was assumed to be smoking and not using the inhaler, and if a participant did not return a used inhaler cannister it was assumed that he or she had not used it.

For the final, fifth-year follow-up, participants were asked to attend the clinic twice - once for the usual follow-up visit and a second time for a repeat methacholine challenge. The challenge test was carried out only in participants without serious nonrespiratory disease and $\mathrm{FEV}_{1} 50 \%$ predicted normal or greater, and was scheduled at least $40 \mathrm{~h}$ after the first visit and cessation of inhaler therapy.

Data management and statistical analysis: All data were collected, checked and analyzed by an independent Data Co-ordinating Center (DCC). For quality control, the DCC generated periodic reports on the progress of the study, which were transmitted to the clinical centres. These reports, plus those containing outcome measures such as lung function, morbidity and mortality, were reviewed by a Safety and Data Monitoring Board, which was an independent body charged with monitoring the success of the trial and stopping it in the case of untoward events or an early clearcut result. Early termination of the LHS was not recommended.

Changes in FEV 1 from baseline (second screen) through the fifth annual visit were analyzed in several ways. Cumulative differences among treatment groups were analyzed by $t$ tests. Detailed treatment of the data was achieved by using random effects models of Laird and Ware (8). The best of these was in the form of a hockey stick with a change in FEV , 
TABLE 2

Biochemically validated smoking cessation rates (\%)

\begin{tabular}{crrrrrr}
\hline $\begin{array}{c}\text { Annual } \\
\text { visit (year) }\end{array}$ & \multicolumn{3}{c}{ Cross-sectional } & \multicolumn{3}{c}{ Sustained } \\
\hline 1 & 34.8 & SIP & \multicolumn{1}{c}{ UC } & SIA & SIP & UC \\
2 & 33.4 & 9.0 & 34.8 & 34.4 & 9.0 \\
3 & 34.1 & 35.1 & 12.8 & 27.9 & 28.2 & 6.8 \\
4 & 35.2 & 36.1 & 14.7 & 24.4 & 25.6 & 5.6 \\
5 & 37.5 & 37.4 & 21.4 & 21.4 & 22.3 & 5.3 \\
\hline
\end{tabular}

*Participants not attending any given annual visit are counted as smokers. SIA Smoking intervention plus bronchodilator; SIP Smoking intervention plus placebo; UC Usual care

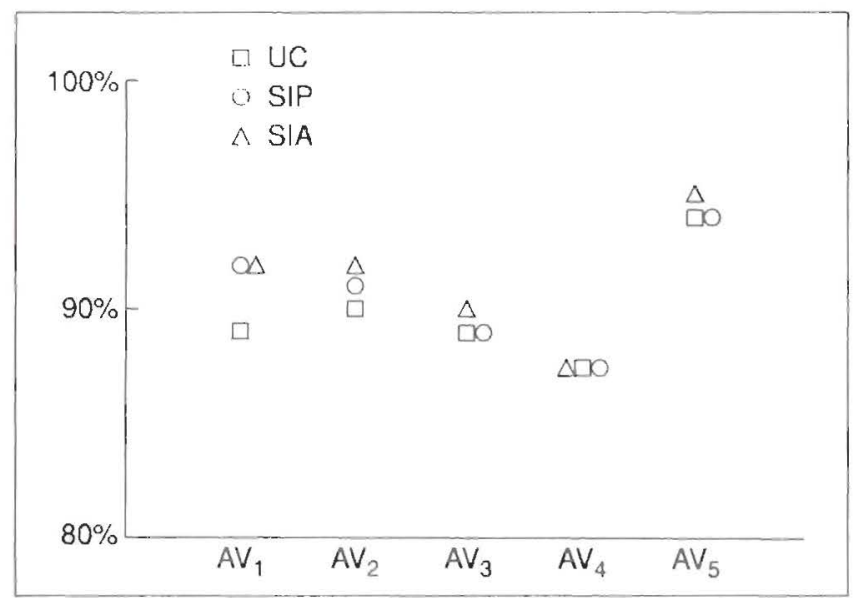

Figure 1) Follow-up rates: percentage of participants completing spirometry at five anmual visits (AV I-5). SIA Smoking intervention plus bronchodilator; SIP Smoking intervention plus placebo: UC Usual iare

between baseline and year 1 and an independent linear change from year 1 through year 5 . Such a model was applied to each participant before group data were pooled. Group differences were assessed by one-sided tests of significance. Other models involving a simple linear decline of FEV fit the data less well than the one cited above. Treatments of the data designed to equalize the influence of individuals with incomplete as opposed to complete measurements did not change the basic result.

\section{RESULTS}

Selected baseline characteristics of the three groups ate shown in Table I. The average age of participants was 48 years. There was an even age distribution except for the group aged 35 to 39 , which was slightly underrepresented with $12 \%$ of the participants as opposed to an 'expected' $20 \%$. Over a third of participants were women. Participants were heavy smokers who averaged more than 30 cigarettes a day at study entry and who had accumulated an average of about 40 pack-years since starting smoking in late adolescence. The FEV 1 was at the lower limit of normal and changed relatively little with bronchodilator. As expected, $\mathrm{FEV} / \mathrm{FVC}$ was clearly in the range indicating airways obstruction. While relatively few of the participants had been fold they had asthma or emphysema, a large fraction hald it
TABLE 3

Inhaler compliance: Percentage satisfactory compliance at each annual visit

\begin{tabular}{ccccc}
\hline Annual & \multicolumn{2}{c}{ SIA } & \multicolumn{2}{c}{ SIP } \\
visit (year) & Self-report & $\begin{array}{c}\text { Canister } \\
\text { weight }\end{array}$ & Self-report & $\begin{array}{c}\text { Canister } \\
\text { weight }\end{array}$ \\
\hline 1 & 61.6 & 47.8 & 62.6 & 48.0 \\
2 & 58.9 & 44.8 & 60.8 & 46.2 \\
3 & 55.4 & 12.9 & 56.4 & 42.5 \\
4 & 52.8 & 40.6 & 53.4 & 40.6 \\
5 & 49.3 & 36.8 & 49.2 & 37.9 \\
\hline
\end{tabular}

SIA Smoking intervention plus bronchodilator: SIP Smoking intervention plus placebo

symptom history compatible with chronic bronchitis. and nearly half of the participants gave a history of exposurc to dust and fumes; such exposures were much more common in men than in women. Methacholine responsiveness also showed a prominent sex difference with women being more responsive than men (9). In the LHS as a whole, a third of participants had a PC 20 (the dose required for a $20 \%$ decline in FEV 1) of $5 \mathrm{mg} / \mathrm{mL}$ or less, while $70 \%$ had a PC 20 of 25 $\mathrm{mg} / \mathrm{mL}$ or less. Of individuals eligible for the final end-ofstudy methacholine challenge, successful testing was carried out in about $88 \%$. Treatment groups were well matched in that there were no significant differences in any of the characteristics noted in Table I. The slightly larger fraction of female participants in the SIA group accounted for the slightly lower baseline value of $\mathrm{FEV}_{1}$ in this group (Table 1 ).

Smoking cessation rates are indicated in Table 2. All quit rates were biochemically verified (carbon monoxide or cotinine) and are therefore the minimum possible. Crosssectional quit rates indicate the fraction of participants not smoking at a given time. Sustained quit rates include only subjects who had stopped during the initial cessation program and remained abstinent thereafter; sustained quit rates, like survival, can only decline with time. The five-year sustained quit rate in SIA and SIP groups was similar it about $22 \%$. compared with about $5 \%$ in the UC group. The cross-sectional quit rate was approximately $35 \%$ in the SIA and SIP groups at year I and changed little thereafter, while cross-sectional quit rate steadily increased in the UC group, reaching $20 \%$ by the end of the study.

Inhaler compliance is shown in Table 3, as assessed both by self-report and cannister weight. The first is likely an overestimate, and the second may be an underestimate since it is likely that some compliant participants forgot io bring cannisters into annual visits. Compliance did not differ between SIA and SIP groups and probably approximated $50 \%$ throughout the study. Inhaler associated side effects were few and did not differ between SIA and SIP groups.

Follow-up rates are shown in Figure 1 and were high throughout the LHS. Spirometry was accomplished in about $90 \%$ of the participants at years 1 to 4 and in $94 \%$ of the participants at year 5 . At year 5 only 21 participants were lost to follow-up in that their location and vital status were unknown. 


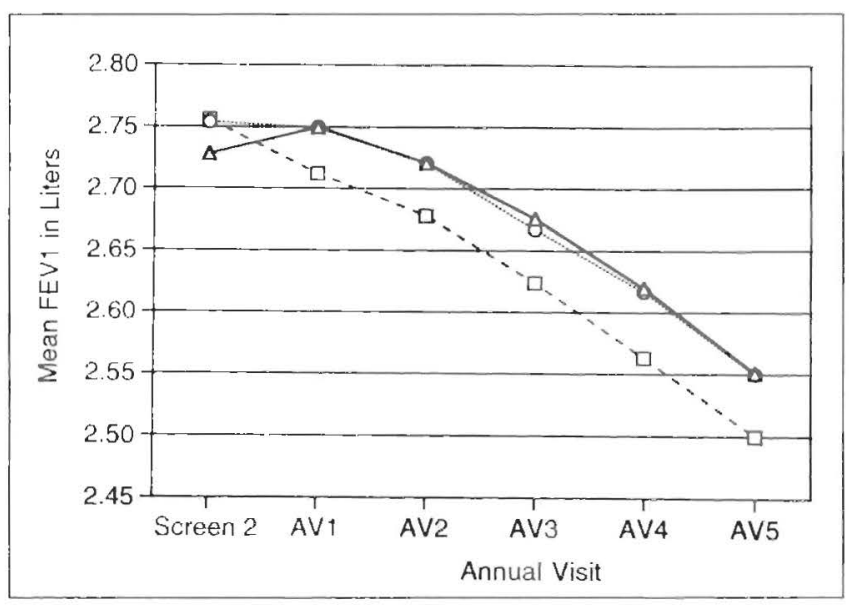

Figure 2) Mean posthronchodilator forced expiratory volume in Is (FEV ) in all available participants at study entry (screen 2) and subsequent annual wisits (AV 1-5). -..- ᄀ-.-Smoking intervention plus bronchodilatur: …… Smoking intervention plus placebo: $-\Delta$ - Usual 'ar' participans: Reproduced with permission firm referenc" 1. copyrigh 1994 American Medical Association

All cause mortality did not differ significantly among treatment groups; 149 participants died - 54 in the SIA group, 44 in the SIP group and 51 in the UC group. As expected, the chief causes of death were lung cancer and cardiovascular disease. There were 18 deaths from cardiovascular disease in the SIA group, 13 in the UC group and seven in the SIP group. These death rates were not significantly different when considered together in a proportional hazards model. However, when SIA and SIP were directly compared using the same model without correction for repeat testing, there was significant difference ( $\mathrm{P}=0.027)$. This was not consistent with other data. Cardiovascular mortality was not related to inhaler compliance and no single diagnosis accounted for the difference between SIA and SIP groups. Hospital morbidity, including that ascribed to cardiovascular disease, differed little among treatment groups, ranging from $8.7 / 100$ personyears of exposure in the SIP group to 9.4 in the UC group. These differences were not significant.

Figure 2 shows average postbronchodilator FEV f for each treatment group at each annual visit. The cumulative change in postbronchodilator $\mathrm{FEV}_{\mathrm{I}}$ was $267 \mathrm{~mL}$ in the $\mathrm{UC}$ group, $209 \mathrm{~mL}$ in SIP and $184 \mathrm{~mL}$ in SIA, each group being different from the other $(\mathrm{P}<0.002)$. Though the $\mathrm{UC}$ group declined in roughly linear fashion, the SIA and SIP group did not; each showed a change in the first year that was different from that of subsequent years. Indeed, in both groups, $\mathrm{FEV}_{1}$ increased slightly in the first year and then fell linearly at a rate not greatly different from that of the UC group.

Results of the change point model developed for these data are shown in Figure 3; this model fitted the data of Figure 2 much better than a simple linear one. Again there were highly significant $(\mathrm{P}<0.001)$ differences among treatment groups when the models of Figure 3 were analyzed. Numerically, during the first year, mean postbronchodilator $F V_{I}$ increased $39 \mathrm{~mL}$ in the SIA group, increased $11 \mathrm{~mL}$ in the SIP group and decreased $34 \mathrm{~mL}$ in the UC group, each

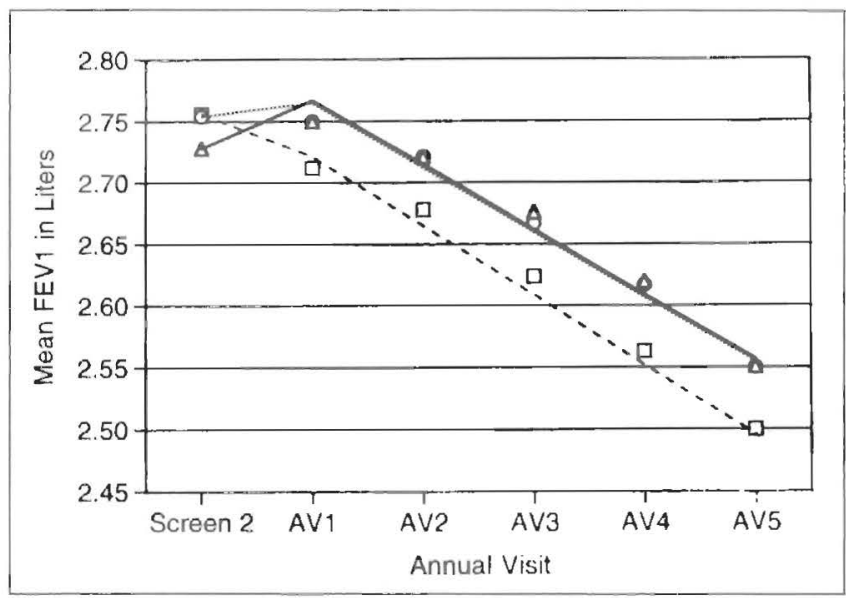

Figure 3) Model of change in posthronchodilator forctel cypiratany volume in I $s\left(F E V_{1}\right)$ in all available participants at suts enery (screen 2) and subsequent annual visits (AV 1-5). Poims are me'm values; lines indicate best fit model of changes in first year followed by linear declines. .-. $\neg$--- Smoking intervention plus bronchodilator; ... - Smoking intervention plus placebo: $-\Delta-$ Usual car' purticipants. Reproduced with permission from referen' '1. copyrigh 1994 American Medical Associurium

change being significantly different $(\mathrm{P}<0.0(1) 5)$ trom the other. Between year $I$ and year 5 all three groups declined; the average rates were $56 \mathrm{~mL} /$ year in the UC group and 52 $\mathrm{mL} /$ year in the other two groups. Pairwise testing gave onesided significance levels of $\mathrm{P}=0.016$ for UC versus SIP, $\mathrm{P}=0.030$ for $\mathrm{UC}$ versus SIA, and $\mathrm{P}=0.399$ for SIA versus SIP.

\section{DISCUSSION}

The three interventions were associated with differences in the study's main outcome variable - change in FEVI. We chose to examine postbronchodilator FEV I because it related best to outcome in COPD $(10,11)$, but changes in prebronchodilator FEV I were very similar and differed among treatment groups. Since the three treatment groups were similar at the start of the study (Table 1), and there was reasonable compliance with the interventions and follow-up was virtually complete, we believe that it is safe to conclude that the differences between groups in change of $\mathrm{FEV}_{1}$ were in fact due to the interventions.

The differences between the SIP and the UC groups were therefore due to a greater degree of smoking cessation in the former than in the latter. In the UC group FEV, fell in an approximately linear way, averaging about $53 \mathrm{mll} /$ year. This occurred even though the cross-sectional quit rate in this group increased steadily (Table 2). If smoking cessation benefits change in FEV 1 as indicated by the SIP-UC difference, then the gradual increase in smoking cessation in the $\mathrm{UC}$ group tended to minimize the fall of $\mathrm{FEV}_{\mathrm{I}}$ in this group. and participants who smoked throughout the study experienced a greater loss of lung function than did the UC group.

The SIP group, on the other hand, experienced essentially no change in $F E V_{1}$ in the first year, but thereafter the FEV 1 of the SIP group fell linearly at a rate only slightly less than that of the UC group. About $35 \%$ of the SIP group stopped 
smoking in the first year, and in these individuals the FEV actually increased slightly $(57 \mathrm{~mL})$, a phenomenon that has been noted previously $(12,13)$. This effect was large enough to prevent the FEV 1 of the SIP group from falling in the first year. After the first year, the cross-sectional rate of smoking cessation changed little in the SIP group; further smoking cessation was essentially balanced by relapse to the habit. Therefore, change in FEV 1 after the first year was that for a group composed of about $65 \%$ smokers and $35 \%$ nonsmokers, and was presumably considerably greater than that of sustained nonsmokers.

The UC and SIP data shown in Figures 2 and 3 failed to diverge because the majority of both groups were smokers, and after the first year smoking cessation actually increased more in the UC than in the SIP group. This is illustrated by comparing 'pure cultures' of quitters and smokers from the SIP group (Figure 4). Here the curves diverge sharply, with continuous smokers' $\mathrm{FEV}_{1}$ declining at a rate greater than $60 \mathrm{~mL} /$ year while sustained quitters lost only $74 \mathrm{~mL}$ over the entire five years. Caution should be exercised in interpreting these data, since there was no random allocation of the sustained quitters and continuous smokers of Figure 4, as exemplified by the slightly lower baseline $\mathrm{FEV}_{1}$ of the smokers.

Differences in change of $\mathrm{FEV}_{1}$ between the SIA and the SIP groups were due to the bronchodilator medication used by the former, since their smoking cessation rates were essentially the same. The difference was confined to the first year, when postbronchodilator $\mathrm{FEV}_{1}$ increased by an average of $40 \mathrm{~mL}$ in the SIA group, as opposed to no change in the SIP group. After the first year data from the SIA and SIP groups were virtually superimposed. At the end of five years the SIA group had undergone a significantly smaller decline (about $25 \mathrm{~mL}$ ) in FEV! than had the SIP group.

There are two possible general interpretations of these results. First, bronchodilator therapy may have changed the course of the disease in some fundamental, long-lasting way. If this were the case, then one might have expected results from the SIA and SIP groups to diverge, and the failure of divergence argued against this interpretation, though divergence might have been masked by a gradual reduction in inhaler compliance. On the other hand, it is possible to interpret the differences between SIA and SIP groups as due to an 'acute' bronchodilator effect. That is, participants in the SIA group had a residual bronchodilator effect at the time of follow-up testing and people in the SIP group did not. This explanation would account for the 'one time' first year gain in function noted in the SIA group. On the other hand, participants were instructed not to use their study inhalers on the day of follow-up testing so any residual bronchodilator effect would have to exceed $12 \mathrm{~h}$ duration, considerably longer than the accepled duration of action of ipratropium bromide (14).

The simplest and best way to assess the importance of the SIA-SIP difference would be to restudy the two groups after both had discontinued their inhalers, since long-lasting bencfit of bronchodilator therapy would presumably still be evident. Fortunately, we were able to carry out this assessment

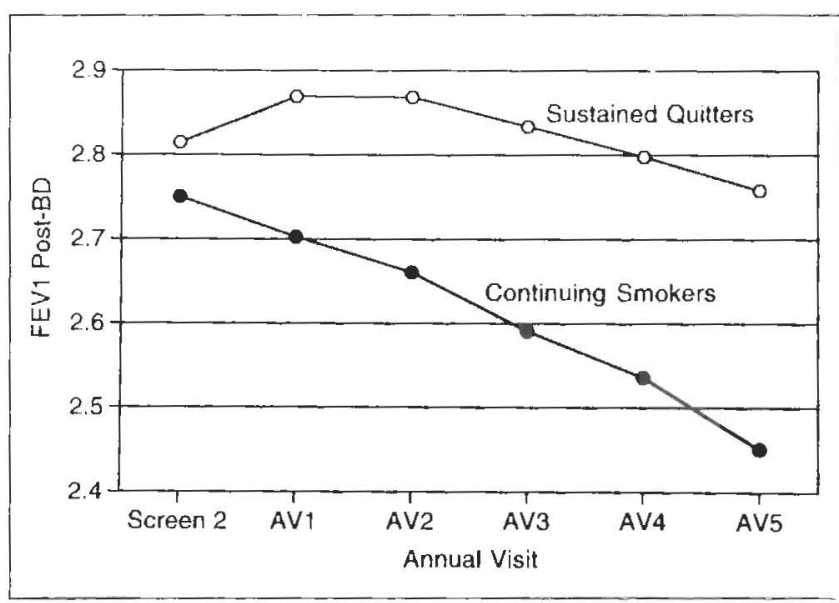

Figure 4) Mean pesthenchodilatur (BD) forced expiratory volum in I $s\left(F E V_{1}\right)$ for smoking intervention plus placebo participants who were sustained quitters (O) or continuous smokers (O). Reproduced from reference I, copyright 1994 American Medical Association

in most participants when they attended the second fifth annual visit for measurement of methacholine response. At the second fifth annual visit all participants were required to have stopped using their inhalers for $40 \mathrm{~h}$, and the vast majority had not used the inhalers for at least a week. Becausc no postbronchodilator spirometry was available at the second fifth annual visit, it was necessary to compare prebronchodilator $\mathrm{FEV}_{\mathrm{I}}$ values. In the SIA group mean prebronchodilator FEV I declined $172 \mathrm{~mL}$ belween baseline and the first fifth annual visit, significantly less than the analogous mean decline of $187 \mathrm{~mL}$ in the SIP group. The difference between the two groups was entirely ascribable to a difference in the first year of the study. However, when decline was measurcd between baseline and the second fifth annual visit, when the SIA group had been off their inhalers for at least $40 \mathrm{~h}$, the mean decline in this group was $200 \mathrm{~mL}$, not significantly different from the analogously measured mean decline of $196 \mathrm{~mL}$ in the SIP group. Put another way, between the first and second fifth annual visits, prebronchodilator FEV $1 \mathrm{dc}-$ clined by an average of $9 \mathrm{~mL}$ in the SIP group and by an average of $36 \mathrm{~mL}$ in the SIA group (P<0.001). Thus, the lirst year advantage of some $30 \mathrm{~mL}$ in the SIA group compared with the SIP group was lost at year 5 when the SIA group abstained from ipratropium for more than $40 \mathrm{~h}$. This was compatible with SIA-SIP differences in FEV (Figures 2 and 3) being due to a residual small pharmacological effect of ipratropium that was rendered significant by the latge number of individuals studied. It is worth noting that a similar mechanism may have applied to other studies, apparently indicating long term benefits of bronchodilator therapy (2).

By virtue of the LHS entry criteria, death was an uncommon event during the study. There was a disconcerting difference in cardiovascular mortality, with the SIA group exceeding the SIP group. We do not helieve this difference should be interpreted as indicating a truc increased risk of ipratropium therapy. The mortality difference achieved significance only when tested inappropriately without correc- 


\section{APPENDIX \\ LUNG HEALTH STUDY RESEARCH GROUP}

Case Western Reserve University, Cleveland, OH MD Altose $\mathrm{MD}\left(\mathrm{PI}{ }^{*}\right)$; AF Connors MD (Co-PI); S Redline MD (Co-PI); C Deitz PhD; RF Rakos PhD

Henry Ford Hospital, Detroit, MI WA Conway Jr MD (PI); A DeHorn PhD (CoPI); JC Ward MD (former Co-PI); CS Hoppe-Ryan CSW; RL Jentons MA; JA Reddick RN; C Sawicki RN MPH

John Hopkins University School of Medicine, Baltimore, MI) RA Wise MD (PI); S Permutt MD (CoPI); CS Rand PhD (Co-PI) Mayo Clinic, Rochester, MN PD) Scanlon MD (PI); LJ Davis PhD (Co-PI); RD Miller MD (Co-PI); DE Williams MD

(Co-PI); GM Caron; GG Lauger MS; SM Toogood (Pulmonary Function Quality Control Manager)

Oregon Health Sciences University, Portland, OR AS Buist MD (PI); WM Bjornson MPH (Co-PI); L.R Johnson PhD (L.HS Pulmonary Function Coordinator)

University of Alabama at Birmingham WC Bailey MD (PI); CM Brooks EdD (Co-PI); JJ Dolce PhD; DM Higgins;

MA Johnson; CD Lorish PhD; BA Martin

University of California, Los Angeles, CA DP Tashkin MD

(PI); AH Coulson (Co-PI); H Gong MD (former Co-PI);

PI Harber MD (Co-PI); VC Li PhD MPH (Co-PI); M Roth MD

(Co-PI); MA Nides PhD; MS Simmons; I Zuniga

University of Manitoba, Wimnipeg, MB NR Anthonisen MD

(PI, Steering Committee Chair); J Manfreda MD (Co-PI);

RP Murray PhD (Co-PI); SC Rempel-Rossum; JM Stoyko
University of Minnesota Coordinating Center, Minneapolis, MN JE Connett PhD (PI); MO Kjelsberg PhD) (Co-PI);

MK Cowles MS; DA Durkin; PL Enright MD; KJ Kurnow MS; WW Lee MS; PG Lindgren MS; SJ Mongin MS; P O'Hara PhD (LHS Intervention Coordinator); HT Voclker; LA Waller PhD) University of Pittsburgh, Pittsburgh, PA GR Owens MD (PI); RM Rogers MD (Co-PI); JJ Johnston PhD; FP Pope MSW; FM Vitale MA

University of Utah, Salt Lake City, UT RE Kanner MD (PI); MA Rigdon PhD (Co-PI); KC Benton; PM Grant (The Salt Lake City Center has been assisted by the Clinical Research Center, Public Health Research Grant M01-RR00064 from the National Center for Research Resources)

Safety and Data Monitoring Board M Becklake MD; B Burrows MD; P Cleary PhD; P Kimbel MD (Chairperson; deceased October 27, 1990); L Nett RN RRT (former member); JK Ockene PhD; RM Senior MD (Chairperson); GL. Snider MD; W Spizer MD (former member); OD Williams PhD National Heart, Lung and Blood Institute Staff, Bethesda, MD SS Hurd PhD (Director, Division of Lung Diseases); JP Kiley PhD (Project Officer); MC Wu PhD) (Division of Epidemiology and Clinical Applications)

Mortality and Morbidity Review Board SM Ayres MD; RE Hyatt MD; BA Mason MD

*PI Prinicipal Investigator tion for oher tests, ic, it was only significant when tested in a post-hoc way. Further, the mortality difference was unsupported by other L.HS datal it was not prominent in inhaler compliant individuals, and it was not mirrored by differences in cardiovascular morbidity between SIA and SIP groups. Finally, the mortality dilference did not make sense, sinco very little inhaled ipratropium is absorbed and cardiovasculat side effects with the drug are virtually unknown (15).

The LHS did show that a vigorous smoking cessation program applied to randomly assigned smokers with mild to moderate airways obstruction can change the rate of deterioration of lung function. Indeed, when examined in "pure culture' (Figure 4) the eflects of smoking cessation were surprisingly large; on average, we would not expect our sustained quitters ever to develop symptomatic disease.

The LHS also showed that regular use of ipratropium bromide produced a 'one time' increase in FEV that disappeared after the drug had been discontinued for several days. Bronchodiator therapy, at least with ipratropium, did not produce long term change, beneficial or otherwise, in lung function. This, of course, in no way challenges the short lerm bencfit of bronchodilators in symptomatic paticnts, benefits that underlic bronchodilator therapy in clinical pratedice. The I.HS, if anything, supports this clinical practice by indicating that ipratropium therapy has no negative long term influence on lung liunction.
Our smoking cessation program was more successlul than any other large, well documentcd cflort, given that our average participant was a long term heavy smoher. It is impositble to be sure which were the most important components of our cessation program. but it is likely that the aggressive use of nicotine substitution therapy was one of them. However, "success" with the best smoking cessation program is not brillant; ours produced a sustained quit rate of $22 \%$. Perhaps of greater significance was the rising quit rate in the UC group - one hopes that this rellected overall sociclal change.

\section{CONCLUSIONS}

We have summarized the main outcomes of the LHS - the tests of the hypotheses it posed. There will be many more outcomes of great interest to the pulmonary community. The L.HS was the first major study of tobace(-related discalses to recruit a substantial number of women and therefore alfords the lirst opportunity to study prospectively these diseases in women. Striking evidence that women are not the same as men has already been uncovered in the form of the greatly increased methacholine sensitivity observed in female as opposed to male LHS participants (9). Also. the LHS should go a long way towards setlling the relative importance of airways reactivity as a risk factor for COPD. Methacholine reactivily was measured at the onset of the study, so that its influence on subseguent decline of lung lunction and is 
interactions with tobacco exposure should become evident. On the other hand, since methacholine challenges were also carried out at the end of the study the influence of disease progression on airways reactivity should also be ascertainable. The effects of smoking and smoking cessation will be analyzed in far greater detail; dose effects will be enumerated and the "acute" short term improvement in lung function with quitting will be closely examined. The effects of age and occupational history upon change in lung function will be

ACKNOWLEDGEMENTS: This study was supported by contract N0I-HR046002 from the Division of Lung Diseases of the National Heart, Lung, and Blood Institute.

\section{REFERENCES}

I. Anthonisen NR, Connett J, Kiley JP, et al. Effects of smoking intervention and the use of an inhaled anticholinergic bronchodilator on the rate of decline of FEV 1 . JAMA 1994;272:1497-505.

2. Anthonisen NR, Wright EC, and the IPPB Trial Group. Bronchodilator response in chronic obstructive pulmonary disease. Am Rev Respir Dis 1986;133:814-9.

3. Sluiter HJ, Koeter GH, de Monchy JGR, Postuma DS, de Vries K, Orie NGM. The Dutch Hypothesis (chronic non-specific lung disease) revisited. Eur Respir J 1991;4:479-89.

4. Connett JE, Kusek JW, Bailey WC, O'Hara P, Wu M, for the Lung Health Study Research Group. Design of the Lung Health Study: A randomized clinical trial of early intervention for chronic obstructive pulmonary disease. Controlled Clin Trials 1993; 14:3S-19S.

5. Durkin DA, Kjelsberg MO, Buist AS, Connett JE, Owens GR, and Recruitment Directors of the Lung Health Study for the Lung Health Study Research Group. Recruitment of participants in the Lung Health Study, I: Description of methods. Controlled Clin Trials 1993:14:20S-37S.

6. Enright PL, Johnson LR, Connett JE, Voelker H, Buist AS. Spirometry in the Lung Health Study: 1. Methods and quality control. Am Rev Respir Dis 1991: 143: 1215-23. studied. Finally, blood samples have been acquired from the vast majority of participants; parsimonious analysis of these samples as recommended by the pulmonary community may give us new insights into host factors important in COPD.

The above is only a partial list of what will be achieved through use of the enormous body of data accumulated by the LHS. It is also worth noting that in accumulating these data the LHS has set a standard for excellence in completing large complicated multicentre trials.

7. O’Hara P. Grill J, Rigdon MA, Connett JE, Langer (AA. Johnston JJ, for the Lung Health Study Research Group. Design and results of the initial intervention program for the Lung Health Study. Prev Med 193;22:304-15.

8. Laird NM, Ware JH. Random effects models for longitudinal data. Biometrics 1982;38:963-74.

9. Tashkin DP, Altose MD, Bleecker ER, et al for the Lung Health Study Research Group. The Lung Health Study: Airway responsiveness to inhaled methacholine in smokers with mild to moderate airflow limitation. Am Rev Respir Dis 1992; 145:301-10.

10. Burrows B, Earle RH. Prediction of survival in patients with chronic airways obstruction. Am Rev Respir Dis 1969;99:865-71.

11. Anthonisen NR, Wright EC, Hodgkin JE. IPPB Trial Group. Prognosis in chronic obstructive pulmonary disease. Am Rev Respir Dis 1986;133:14-20.

12. McCarthy DS, Craig DB, Cherniack RM. Effect of modification of the smoking habit on lung function. Am Rev Respir Dis 1976;104:103-13.

13. Buist AS, Nagy JM, Sexton GJ. The effect of smoking cessation on pulmonary function: A 30 month follow-up of two smoking cessation clinics. Am Rev Respir Dis 1979;120:953-7.

14. Gross NJ. Sch 1000: A new anticholincrgic bronchodilator. Am Rev Respir Dis 1975;112:823-8.

15. Massey KL, Gotz VP. Ipratropium bromide. Drug Intell Clin Pharm 1985;19:5 12. 


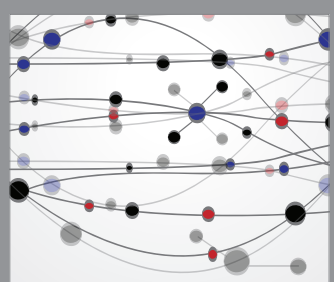

The Scientific World Journal
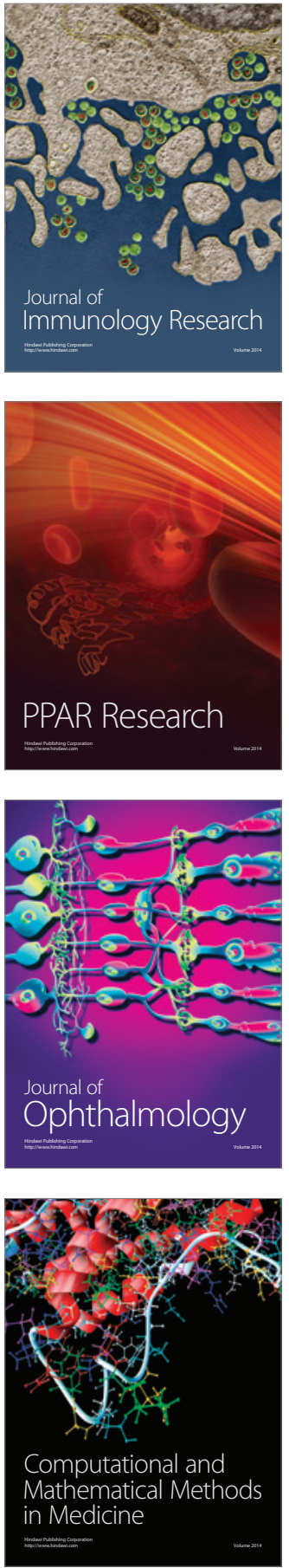

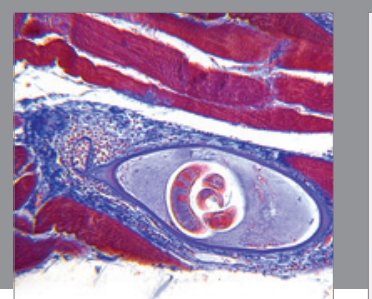

Gastroenterology Research and Practice

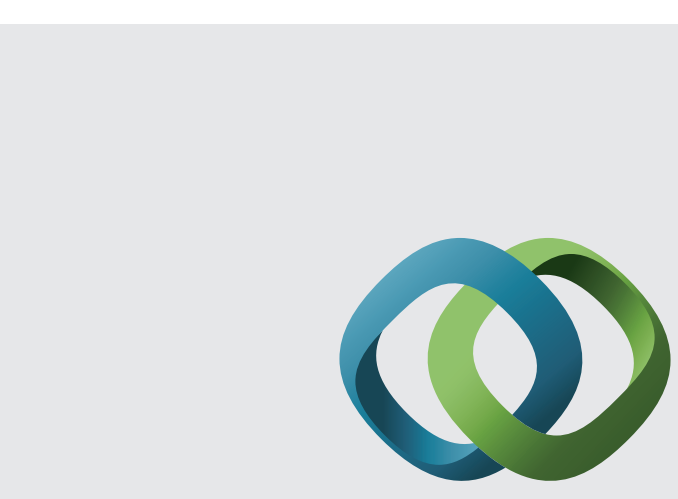

\section{Hindawi}

Submit your manuscripts at

http://www.hindawi.com
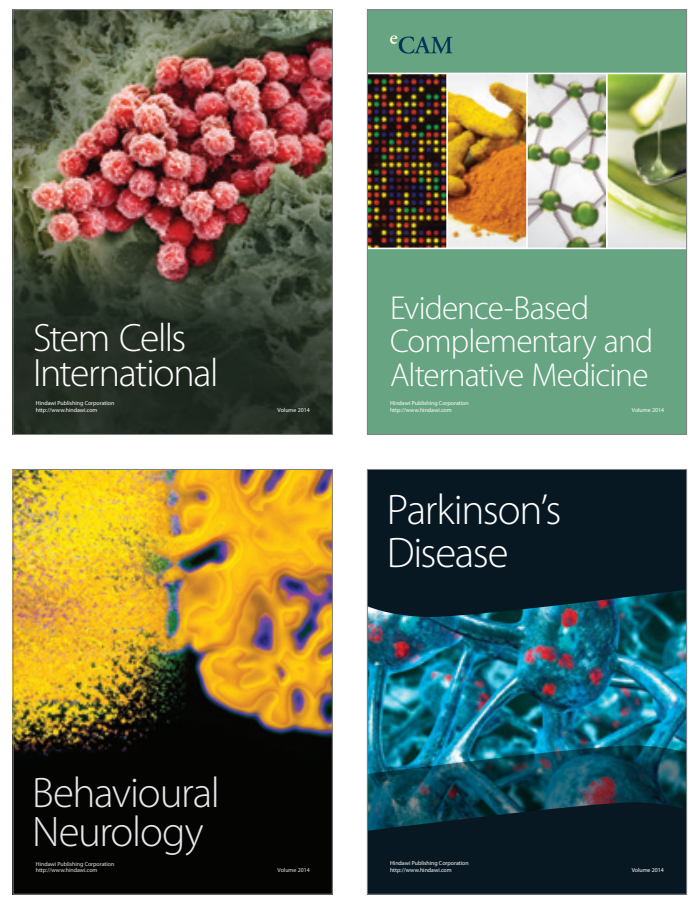
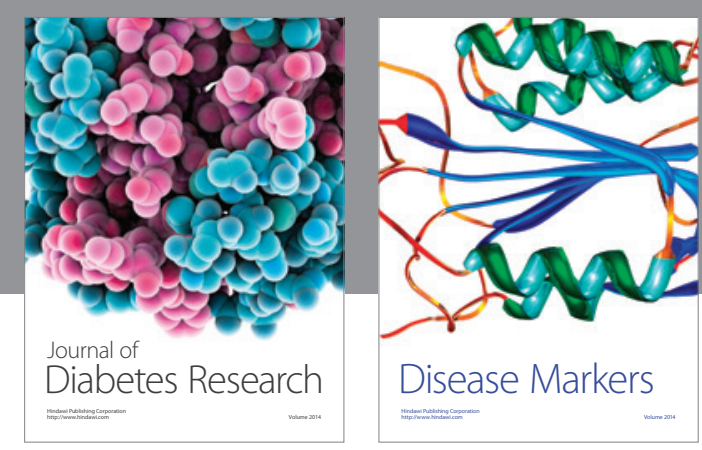

Disease Markers
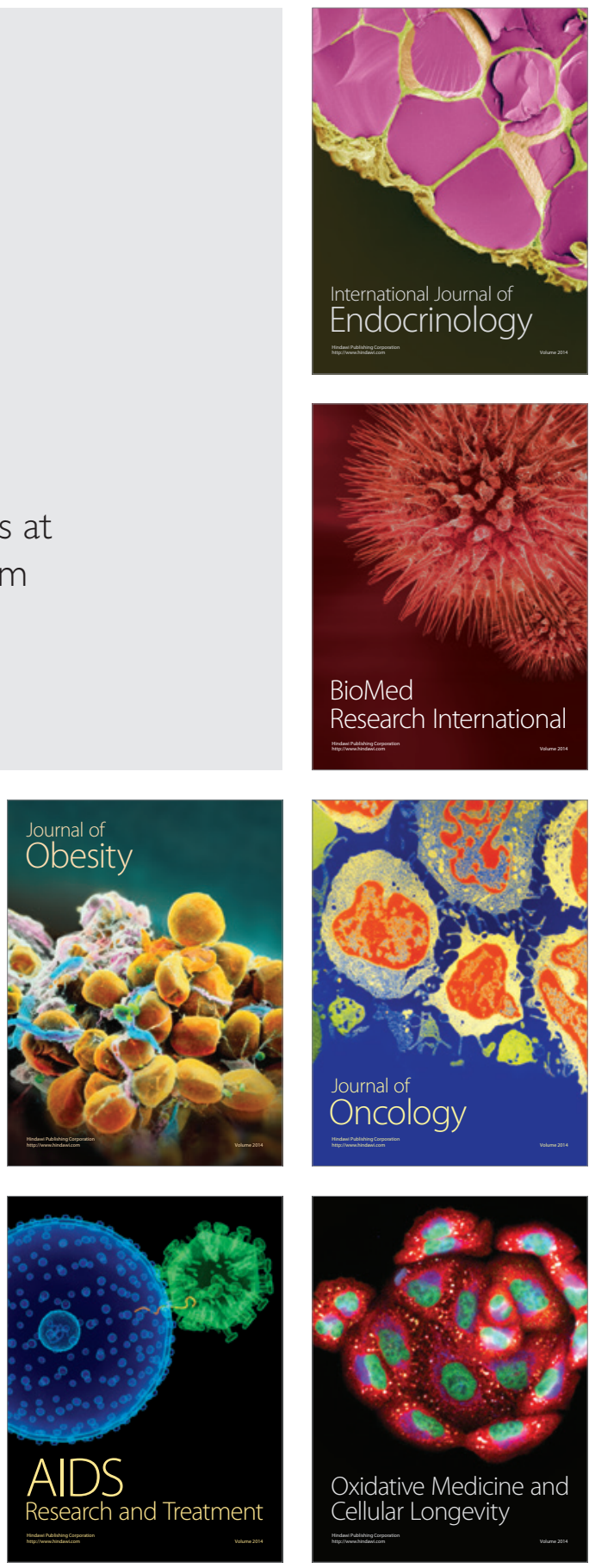